\title{
Ethnic variation in validity of the estimated obesity prevalence using self-reported weight and height measurements
}

\author{
Henriëtte Dijkshoorn ${ }^{1 *}$, Joanne K Ujcic-Voortman ${ }^{1}$, Lucie Viet ${ }^{2}$, Arnoud P Verhoeff ${ }^{1,3}$ and Daan G Uitenbroek
}

\begin{abstract}
Background: We examined ethnic differences between levels of body mass index (BMI) based on self-reported and measured body height and weight and the validity of self-reports used to estimate the prevalence of obesity $\left(\mathrm{BMl} \geq 30 \mathrm{~kg} / \mathrm{m}^{2}\right.$ ) in Turkish, Moroccan, and Dutch people in the Netherlands. Furthermore, we investigated whether BMI levels and the prevalence of obesity in Turkish and Moroccan people with incomplete self-reports (missing height or weight) differ from those with complete self-reports.

Methods: Data on self-reported and measured height and weight were collected in a population-based survey among 441 Dutch, 414 Turks and 344 Moroccans aged 18 to 69 years in Amsterdam, the Netherlands in 2004. BMI and obesity were calculated from self-reported and measured height and weight.

Results: The difference between measured and estimated BMI was larger in Turkish and Moroccan women than in Dutch women, which was explained by the higher BMI of the Turkish and Moroccan women. In men we found no ethnic differences between measured and estimated BMI. Sensitivity to detect obesity was low and specificity was high. In participants with available self-reported and measured height and weight, self-reports produced a similar underestimation of the obesity prevalence in all ethnic groups. However, many obese Turkish and Moroccan women had incomplete self-reports, missing height or weight, resulting in an additional underestimation of the prevalence of obesity. Among men (all ethnicities) and Dutch women, the availability of height or weight by selfreport did not differ between obese and non obese participants.

Conclusions: BMI based on self-reports is underestimated more by Turkish and Moroccan women than Dutch women, which is explained by the higher BMI of Turkish and Moroccan women. Further, in women, ethnic differences in the estimation of obesity prevalence based on self-reports do exist and are due to incomplete selfreports in obese Turkish and Moroccan women. In men, ethnicity is not associated with discrepancies between levels of BMI and obesity prevalence based on measurements and self-reports. Hence, our results indicate that using measurements to accurately determine levels of BMI and obesity prevalence in public health research seems even more important in Turkish and Moroccan migrant women than in other populations.
\end{abstract}

\section{Background}

Obesity is a major problem for public health. It is associated with many chronic diseases, such as cardiovascular diseases and diabetes mellitus [1]. One group of people at high risk of obesity are non-western migrants in western societies. Among these groups, the prevalence of excessive

\footnotetext{
* Correspondence: hdijkshoorn@ggd.amsterdam.nl

${ }^{1}$ Public Health Service of Amsterdam, Department of Epidemiology, Documentation and Health Promotion, P.O. Box 2200, 1000 CE Amsterdam, the Netherlands

Full list of author information is available at the end of the article
}

weight is often higher than among host populations [2,3]. In Europe, migrants from Turkey and Morocco are among the largest ethnic minority groups. Turkish migrants mainly live in Germany and the Netherlands and Moroccan migrants in France, Belgium and the Netherlands [4]. In Amsterdam (the Netherlands), Turkish and Moroccan migrants represent $5 \%$ and $9 \%$ respectively of the total population [5]. Earlier studies have reported that Turkish and Moroccan migrant groups, in particular women, are at high risk of overweight and obesity [6-10]. Therefore, continued monitoring of the prevalence of obesity in these

\section{Biomed Central}


population groups is of great importance. However, although Turks and Moroccans constitute a substantial part of migrant populations in many European countries, they are often poorly represented in epidemiological studies [11]. Objective data based on physical examinations to back up self-reports are scarce [12] and available data are limited to a selected subpopulation, for example, the Turks, mothers of young children or young adults $[7,9,13]$.

Many population-based surveys use self-reported body weight and height to determine the prevalence of obesity, mainly because of financial and logistical limitations. However, since people tend to under-report their body weight and to over-report their body height, this most likely results in an underestimation of obesity prevalence [14-18]. Several studies have suggested that the validity of self-reported body weight and height to estimate the prevalence of obesity differs across cultures [19-23]. The validity of the use of self-reports to estimate obesity prevalence rates among Turkish and Moroccan adult migrants has not previously been reported, whereas there are further concerns about its validity, because the percentage of missing self-reports among Turkish and Moroccan migrants appears to be higher compared with the Dutch population, in particular among low educated and elderly migrant women [8]. This might affect the estimated obesity prevalence considering the association of overweight with education and age [12].

This study aims to examine ethnic differences between levels of BMI based on self-reported and measured body height and weight and the validity of self-reports to estimate obesity prevalence in Turkish, Moroccan, and Dutch people in the Netherlands. Furthermore, we have investigated whether BMI levels and obesity prevalence in Turkish and Moroccan people with missing selfreported height or weight differ from those with complete self-reports. As such, our study provides new evidence for public health researchers and policymakers about ethnic variation in the validity of self-reported weight and height to estimate the obesity prevalence.

\section{Methods}

\section{Study population}

Data from a Dutch multiethnic population-based survey, the Amsterdam Health Monitor 2004, were examined [24]. In this health monitor both self-reported and measured data on body weight and height were collected in 2004 as part of a general health survey among the adult population (18+). The study was conducted by the Public Health Service of Amsterdam in collaboration with the National Institute for Public Health and the Environment. The study sample was drawn from the municipal register of five districts in Amsterdam. The populations from these five districts combined was representative of the total
Amsterdam population. The sample was stratified by age (18-34 years; 35-44 years; 45-54 years; $55-64$ years and 65 years and older) and ethnicity (Dutch, Turkish, Moroccan, and others). The individuals in the sample were invited to come to an interview and a medical examination in a local childcare center. All interviews were conducted in the language of choice of the respondent i.e. Dutch, Turkish, Moroccan-Arabic or Berber. The interviews were based on a structured questionnaire that was translated forwards and backwards from Dutch to Turkish and Arabic by certified translators.

The final response rate was 45\%; Dutch 46\%, Turkish $50 \%$, and Moroccan 39\%. In total 1,736 inhabitants of Amsterdam participated, of whom 518 were Dutch, 446 Turkish and 365 Moroccan. Because of the low numbers of participants aged 70 years and over $(n=93)$, especially among migrant groups, these people were excluded from analyses. Participants with missing data on age, measured body weight or height, pregnant women and participants with out of range data $(n=37)$ on body weight $(<25 \mathrm{~kg}$ or $>300 \mathrm{~kg})$, height $(<50 \mathrm{~cm}$ or $>250 \mathrm{~cm})$ or BMI $\left(<14 \mathrm{~kg} / \mathrm{m}^{2}\right.$ or $\left.>60 \mathrm{~kg} / \mathrm{m}^{2}\right)$ were also excluded. Consequently, the final study population consisted of 1,199 participants aged 18 to 69 years of whom 441 Dutch, 414 Turkish and 344 Moroccan.

Informed consent was obtained from participants during the health examination. Participants received written information including an explanation that the measurement of weight and height was part of the physical examination. The study protocol was approved by the Medical Ethical Committee of the Academic Medical Centre, University of Amsterdam.

\section{Measurements}

Among a wide variety of health-related items, body height (in $\mathrm{cm}$ ) and weight (in $\mathrm{kg}$ ) were recorded in the questionnaire. The measurements in the health examination were taken by a trained nurse and took place immediately following the interview. Participants were dressed in light indoor clothing with emptied pockets and no shoes or hats. Height was measured without shoes, with the respondent looking straight ahead, heels connecting and feet at an angle of $45^{\circ}$ with a wall mounted stadiometer to the nearest $0.5 \mathrm{~cm}$. Weight was measured to the nearest $0.5 \mathrm{~kg}$ on calibrated analogue scales. To adjust for the weight of clothing, one kilogram was subtracted from the body weight. BMI was computed as weight divided by squared height in $\mathrm{kg} / \mathrm{m}^{2}$. Obesity was defined as BMI $\geq$ $30.0 \mathrm{~kg} / \mathrm{m}^{2}$, according to WHO-criteria [1]. Both the true obesity prevalence based on measured body weight and height and the estimated obesity prevalence based on selfreported weight and height were calculated. Data on socioeconomic and demographic background concerned gender, age, highest level of education (primary school or less 
vs. secondary education or higher), income level (below standard vs. higher; standard is net household income $€ 1,350.00$ per month), and ethnicity (Dutch, Turkish, and Moroccan). Dutch was defined as people with both parents born in the Netherlands. Turkish and Moroccan ethnicity comprised people themselves born in Turkey or Morocco or at least one of their parents. All countries of birth referred to the self-reported country of birth. To guarantee the correctness of the data, all entered data were checked immediately after data entry [24].

\section{Statistical analysis}

For the total study population, descriptive statistics were computed, including mean measured and self-reported body weight, height and BMI, true and estimated obesity prevalence and number of missing items by gender and ethnic group. A Chi-squared test was performed to study differences between the true obesity prevalence of participants with and without available self-reports. In further analyses, participants with incomplete selfreports were excluded. A paired $t$-test was used to examine differences between self-reported and measured body weight, height and BMI, after assessing normality. Because of unequal variances, the Kruskall Wallis Test was used to examine ethnic differences. Ethnic differences in true and estimated obesity prevalence were studied with a Chi-squared test. Sensitivity and specificity for determining obesity from self-reported data were calculated. The association of Turkish or Moroccan ethnicity (ref: Dutch) with the difference between selfreported and measured BMI as dependent variable (model 1) was analyzed with linear regression analyses separately for men and women. Subsequently, age was added in model 2, measured BMI in model 3 and educational level (ref: secondary education or higher) in model 4. All statistical analyses were performed with SPSS Windows 17.0.

\section{Results}

\section{Characteristics of the study population}

The crude characteristics of all 1,199 participants are summarized in table 1. Moroccan men were older than their Dutch counterparts and Turkish and Moroccan women younger. Educational and income level were relatively low in the Turkish and Moroccan compared to the Dutch participants. Table 1 also shows mean self-reported and measured body height, weight, BMI, and obesity prevalence rates based on self-reported and measured data. Turkish and Moroccan women had a lower measured and selfreported height than Dutch women in our sample, whereas measured and self-reported body weight and BMI were higher. In men, no ethnic differences in measured and self-reported body weight were found. However, mean measured and self-reported body height was lower and
Table 1 Characteristics of the study population by sex and ethnic group

\begin{tabular}{|c|c|c|c|c|}
\hline & Dutch & Turkish & Moroccan & \\
\hline Men & $(n=183)$ & $(n=197)$ & $(n=184)$ & $\mathrm{p}$ \\
\hline \multicolumn{5}{|l|}{ Demography } \\
\hline age $(y \pm s d)$ & $47.3(12.3)$ & $48.3(12.6)$ & $51.4(12.6)$ & 0.003 \\
\hline$\leq$ primary education & $13.3 \%$ & $56.6 \%$ & $63.3 \%$ & $<0.001$ \\
\hline low income $e^{a}$ & $24.9 \%$ & $72.6 \%$ & $82.7 \%$ & $<0.001$ \\
\hline \multicolumn{5}{|l|}{ Anthropometry } \\
\hline \multicolumn{5}{|l|}{ height } \\
\hline measured (cm $\pm \mathrm{sd})$ & $179.6(7.0)$ & $168.6(6.5)$ & $171.6(6.6)$ & $<0.001$ \\
\hline self-reported $(\mathrm{cm} \pm \mathrm{sd})$ & $180.5(7.2)$ & $170.4(6.6)$ & $172.6(6.8)$ & $<0.001$ \\
\hline missing self-reports (n) & $1.6 \%(3)$ & $8.6 \%(17)$ & $16.8 \%(31)$ & $<0.001$ \\
\hline \multicolumn{5}{|l|}{ weight } \\
\hline measured (kg $\pm \mathrm{sd})$ & $81.0(13.0)$ & $78.5(12.3)$ & $79.0(12.3)$ & 0.136 \\
\hline self-reported (kg \pm sd) & $81.0(12.3)$ & $79.4(12.1)$ & $79.0(12.1)$ & 0.240 \\
\hline missing self-reports (n) & $3.3 \%(6)$ & $6.1 \%(12)$ & $10.9 \%(20)$ & 0.013 \\
\hline \multicolumn{5}{|l|}{$B M I$} \\
\hline measured $\left(\mathrm{kg} / \mathrm{m}^{2} \pm \mathrm{sd}\right)$ & $25.1(4.0)$ & $27.6(4.3)$ & $26.8(3.8)$ & $<0.001$ \\
\hline self-reported $\left(\mathrm{kg} / \mathrm{m}^{2} \pm \mathrm{sd}\right)$ & $24.9(3.7)$ & $27.3(4.0)$ & $26.7(3.6)$ & $<0.001$ \\
\hline missing self-reports (n) & $4.4 \%(8)$ & $11.7 \%(23)$ & $22.3 \%(41)$ & $<0.001$ \\
\hline \multicolumn{5}{|l|}{ Obesity } \\
\hline true (measured) & $12.6 \%$ & $26.4 \%$ & $20.7 \%$ & 0.003 \\
\hline estimated (self-reported) & $9.1 \%$ & $23.0 \%$ & $16.8 \%$ & 0.002 \\
\hline Women & $(n=258)$ & $(n=217)$ & $(n=160)$ & \\
\hline \multicolumn{5}{|l|}{ Demography } \\
\hline age $(y \pm s d)$ & $48.2(13.0)$ & $43.0(13.0)$ & $43.5(13.9)$ & $<0.001$ \\
\hline$\leq$ primary education & $19.1 \%$ & $64.5 \%$ & $63.9 \%$ & $<0.001$ \\
\hline income below standard ${ }^{a}$ & $34.8 \%$ & $76.7 \%$ & $76.2 \%$ & $<0.001$ \\
\hline \multicolumn{5}{|l|}{ Anthropometry } \\
\hline \multicolumn{5}{|l|}{ Height } \\
\hline measured $(\mathrm{cm} \pm \mathrm{sd})$ & $166.8(7.0)$ & $156.9(5.4)$ & $159.5(6.4)$ & $<0.001$ \\
\hline self-reported $(\mathrm{cm} \pm \mathrm{sd})$ & $167.6(6.9)$ & $159.7(5.9)$ & $163.0(6.5)$ & $<0.001$ \\
\hline missing self-reports (n) & $1.2 \%(3)$ & $19.8 \%(43)$ & $35.0 \%(56)$ & $<0.001$ \\
\hline \multicolumn{5}{|l|}{ Weight } \\
\hline measured $(\mathrm{kg} \pm \mathrm{sd})$ & $71.8(14.4)$ & $74.7(14.6)$ & $74.8(16.1)$ & 0.021 \\
\hline self-reported (kg \pm sd) & 71.5 (13.6) & $75.0(14.6)$ & $74.3(14.9)$ & 0.010 \\
\hline missing self-reports (n) & $6.6 \%(17)$ & $9.7 \%(21)$ & $19.4 \%(31)$ & $<0.001$ \\
\hline \multicolumn{5}{|l|}{$B M l$} \\
\hline measured $\left(\mathrm{kg} / \mathrm{m}^{2} \pm \mathrm{sd}\right)$ & $25.8(5.0)$ & $30.4(6.0)$ & $29.5(6.3)$ & $<0.001$ \\
\hline self-reported $\left(\mathrm{kg} / \mathrm{m}^{2} \pm \mathrm{sd}\right)$ & $25.6(4.8)$ & $28.9(5.8)$ & $28.2(6.1)$ & $<0.001$ \\
\hline missing self-reports (n) & $7.4 \%(19)$ & $23.5 \%(51)$ & $41.3 \%(66)$ & $<0.001$ \\
\hline \multicolumn{5}{|l|}{ Obesity } \\
\hline true (measured) & $19.8 \%$ & $49.8 \%$ & $47.5 \%$ & $<0.001$ \\
\hline estimated (self-reported) & $16.3 \%$ & $37.3 \%$ & $35.1 \%$ & $<0.001$ \\
\hline
\end{tabular}

${ }^{a}$ net household income below $€ 1,350.00$ per month.

BMI was higher in Turkish and Moroccan men than in Dutch men in our sample. In both men and women, true and estimated obesity prevalence rates were higher among Turks and Moroccans than among Dutch. Furthermore, the relative and absolute number of incomplete selfreported data are displayed in table 1 . BMI could not be 
estimated from self-reports in 72 males (13\%) and 136 females $(21 \%)$, because of missing weight or height by selfreport. Self-reported body height was missing more often than self-reported body weight. The percentage of missing data was highest among Moroccan women, Turkish women and Moroccan men.

Table 2 demonstrates that the obesity prevalence was higher among Turkish (73\%) and Moroccan (58\%) women with incomplete self-reports than among Turkish (43\%) and Moroccan (40\%) women with complete self-reports (Turkish: $\mathrm{p}<0.001$; Moroccan: $\mathrm{p}<0.05$; Chi-squared test). There were no statistically significant differences in the obesity prevalence of men and Dutch women with and without completed self-reports. Low educated Moroccan and Turkish women had incomplete self-reports more often than Moroccan and Turkish women with a minimum educational level of low vocational training ( $\mathrm{p}<0.001$; Chi-squared test, not in table). Incompleteness of self-reported BMI was not associated with measured BMI $(\mathrm{OR}=1.01 ; 95 \%$-CI: 0.98-1.05, not in table).

\section{Use of self-reports to determine obesity prevalence}

In table 3 the differences between self-reported and measured weight, height and BMI are presented. We analyzed data from 991 participants with available self-reported and measured body weight and height. In all subgroups, measured body height was lower than self-reported body height, although in Moroccan men the difference was not statistically significant. The differences between selfreported and measured body height varied between the three ethnic groups, both in men and women. The largest differences were found in Turkish $(-2.5 \mathrm{~cm})$ and Moroccan $(-2.2 \mathrm{~cm})$ women. There were no statistically significant ethnic differences between measured and selfreported body weight. Obese participants under-reported their body weight by $0.6 \mathrm{~kg}$ and their BMI by $1.1 \mathrm{~kg} / \mathrm{m}^{2}$, with no significant differences between the ethnic groups (not in table). In most subgroups true BMI was higher than estimated BMI. The differences between true and estimated BMI were larger among Turkish and Moroccan women than among Dutch women. No ethnic differences between true and estimated BMI were found among men.
Table 3 also shows that in participants with completed self-reports, the method of self-reported body weight and height resulted in an underestimation of obesity prevalence, varying from $2.5 \%$ in Dutch women to $5.5 \%$ in Turkish women with no statistically significant differences between the three ethnic groups. Calculated as a percentage of the true obesity prevalence, the underestimation varied from 13\% in Turkish men and Dutch and Moroccan women to $24 \%$ in Dutch men.

Table 4 explores the sensitivity and specificity for detecting obesity in the three ethnic groups. Sensitivity (78\%; 95\%-CI: 72-85\%) was fairly comparable in the three ethnic groups, but lower among men $(69 \%$;95\%CI: $57-81 \%)$ than women (84\%;95\%-CI: 76-91\%). Highest sensitivity for obesity was found in Dutch women (87\%; 95\%-CI: 74-99\%). Specificity for obesity was high (98\%;95\%-CI: 96-99\%) and hardly differed between the ethnic groups. The highest specificity was found in Dutch men (99\%; 95\%-CI: 98-101\%) and women (100\%; 95\%-CI:100-100\%).

Table 5 presents the results from linear regression analyses. These showed that among men, the difference between true and estimated BMI increased with age and was not associated with ethnicity and educational level (table 5). After including measured BMI in the model, the association with age was no longer significant. Among Turkish and Moroccan women, the difference between true and estimated BMI was larger than among Dutch women and increased with age. The addition of measured BMI to the model explained the ethnic differences and the association with age was no longer significant. Educational level had no effect on the association between ethnicity and the difference between true and estimated BMI.

\section{Discussion}

This study investigated ethnic differences between BMI based on self-reported and measured body height and weight and the validity of self-reports for estimating the prevalence of obesity among Turks, Moroccans and Dutch in the Netherlands. It showed that among Turkish and Moroccan women, the accuracy of BMI based on self-reports was less than among Dutch women, which could be explained by the higher BMI among Turkish

Table 2 Obesity prevalence (\%) in participants with complete and incomplete self-reports ${ }^{\mathrm{a}}$ by ethnicity and gender

\begin{tabular}{lllllll}
\hline & Men & & & Women & \\
& Dutch & Turkish & Moroccan & Dutch & Turkish & Moroccan \\
& $\mathbf{n = 1 8 3}$ & $\mathbf{n}=\mathbf{1 9 7}$ & $\mathbf{n = 1 8 4}$ & $\mathbf{n = 2 5 8}$ & $\mathbf{n}=\mathbf{2 1 7}$ & $\mathbf{n}=\mathbf{1 6 0}$ \\
\hline Participants with complete self-reports & $12 \%$ & $26 \%$ & $21 \%$ & $19 \%$ & $43 \%$ & $40 \%$ \\
Participants with incomplete self-reports & $25 \%$ & $26 \%$ & $20 \%$ & $32 \%$ & $73 \%$ & $58 \%$ \\
Chi $^{2}$-test & 0.278 & 0.971 & 0.838 & 0.179 & $<0.001$ & 0.032 \\
\hline
\end{tabular}

\footnotetext{
${ }^{a}$ Self-reported height and/or weight.
} 
Table 3 Difference between measured and reported weight, height, BMI and obesity prevalence by ethnicity and sex ${ }^{a}$

\begin{tabular}{|c|c|c|c|c|}
\hline & Dutch & Turkish & Moroccan & \\
\hline Men & $(n=175)$ & $(n=174)$ & $(n=143)$ & $p^{\mathbf{b}}$ \\
\hline height difference $(\mathrm{cm} \pm \mathrm{sd})$ & $-0.8(2.3)^{* * *}$ & $-1.8(3.4)^{* * *}$ & $-0.6(3.7)$ & $<0.001$ \\
\hline weight difference $(\mathrm{kg} \pm \mathrm{sd})$ & $-0.1(3.5)$ & $-0.5(3.3)$ & $0.0(3.4)$ & 0.333 \\
\hline BMI difference $\left(\mathrm{kg} / \mathrm{m}^{2} \pm \mathrm{sd}\right)$ & $0.2(1.4)$ & $0.4(1.5)^{* * *}$ & $0.2(1.6)$ & 0.074 \\
\hline obesity difference $(\%, 95 \% \mathrm{Cl})$ & $2.9(1.3 ; 6.6)$ & $3.4(1.6 ; 7.3)$ & $4.2(1.9 ; 8.9)$ & 0.809 \\
\hline underestimation ${ }^{c}(\%, 95 \% \mathrm{Cl})$ & $24.2(18.5 ; 31.1)$ & $12.9(8.7 ; 18.7)$ & $20.0(14.3 ; 27.3)$ & 0.511 \\
\hline Women & $(n=239)$ & $(n=166)$ & $(n=94)$ & \\
\hline height difference $(\mathrm{cm} \pm \mathrm{sd})$ & $-0.7(1.9)^{* * *}$ & $-2.5(3.0)^{* * *}$ & $-2.2(3.8)^{* * *}$ & $<0.001$ \\
\hline weight difference $(\mathrm{kg} \pm \mathrm{sd})$ & $0.0(2.4)$ & $-0.4(2.9)$ & $-0.2(3.9)$ & 0.203 \\
\hline BMI difference $\left(\mathrm{kg} / \mathrm{m}^{2} \pm \mathrm{sd}\right)$ & $0.2(1.1)^{* *}$ & $0.8(1.8)^{* * *}$ & $0.7(2.3)^{* *}$ & $<0.001$ \\
\hline obesity difference $(\%, 95 \% \mathrm{Cl})$ & $2.5(1.1 ; 5.4)$ & $5.5(2.9 ; 10.1)$ & $5.3(2.3 ; 11.8)$ & 0.262 \\
\hline underestimation ${ }^{\mathrm{c}}(\%, 95 \% \mathrm{Cl})$ & $13.3(9.6 ; 18.2)$ & $12.9(8.6 ; 18.9)$ & $13.1(7.7 ; 21.4)$ & 0.994 \\
\hline
\end{tabular}

analyses limited to participants with available data on measured and self-reported height and weight.

${ }^{b}$ p-value of Kruskall Wallis Test on significant differences between ethnic groups.

cunderestimation of the obesity prevalence by self-reports as a percentage of the true prevalence.

${ }^{*} p<0.05 ;{ }^{* *} p<0.01 ;{ }^{* *} p<0.001$ for paired $t$-test on differences between measured and self reported values.

and Moroccan women. Among men, there was no association of ethnicity with the accuracy of BMI based on self-reports. Among women, we also found ethnic differences in the estimation of the prevalence of obesity based on self-reports, due to incomplete self-reports in obese Turkish and Moroccan women. In men, ethnicity was not associated with discrepancies between obesity prevalence based on measurements and self-reports. The sensitivity and specificity for detecting obesity from selfreports was comparable between ethnic groups.

\section{Strengths and limitations}

When interpreting the results of our study its strengths and limitations should be taken into account. Important strengths are the inclusion of a large sample of two well-defined ethnic minority groups, Turks and Moroccans, who could be compared to Dutch people from the same study population. Further, we had the unique opportunity to compare the validity of self-reported data on body weight and height with data collected in a physical examination among these three ethnic groups.

Table 4 Classification of participants into obese or non-obese based on self-reported and measured height and weight $^{\mathrm{a}}$

\begin{tabular}{|c|c|c|c|c|c|c|}
\hline \multirow[t]{2}{*}{ Ethnicity } & \multirow[t]{2}{*}{ Sex } & \multirow{2}{*}{$\begin{array}{l}\text { Estimated } \\
\text { obesity }\end{array}$} & \multicolumn{2}{|c|}{ True obesity } & \multirow{2}{*}{$\begin{array}{l}\text { Sensitivity } \\
(95 \%-C I)\end{array}$} & \multirow{2}{*}{$\begin{array}{l}\text { Specificity } \\
(95 \%-\mathrm{Cl})\end{array}$} \\
\hline & & & no & yes & & \\
\hline \multirow[t]{4}{*}{ Dutch } & men & no & 153 & 6 & $71 \%$ (47-96\%) & $99 \%$ (98-101\%) \\
\hline & $(n=175)$ & yes & 1 & 15 & & \\
\hline & women & no & 194 & 6 & 87\% (74-99\%) & $100 \%(100-100 \%)$ \\
\hline & $(n=239)$ & yes & 0 & 39 & & \\
\hline \multirow[t]{4}{*}{ Turkish } & men & no & 120 & 14 & $70 \%(53-87 \%)$ & $94 \%$ (88-99\%) \\
\hline & $(n=174)$ & yes & 8 & 32 & & \\
\hline & women & no & 92 & 12 & $83 \%$ (72-94\%) & $97 \%$ (92-101\%) \\
\hline & $(n=166)$ & yes & 3 & 59 & & \\
\hline \multirow[t]{4}{*}{ Moroccan } & men & no & 109 & 10 & $67 \%$ (45-88\%) & $96 \%(92-101 \%)$ \\
\hline & $(n=143)$ & yes & 4 & 20 & & \\
\hline & women & no & 54 & 7 & $82 \%$ (66-97\%) & $96 \%(90-103 \%)$ \\
\hline & $(n=94)$ & yes & 2 & 31 & & \\
\hline \multirow[t]{6}{*}{ All } & men & no & 382 & 30 & $69 \%(57-81 \%)$ & 97\% (95-99\%) \\
\hline & & yes & 13 & 67 & & \\
\hline & women & no & 340 & 25 & $84 \%$ (76-91\%) & $99 \%(97-100 \%)$ \\
\hline & & yes & 5 & 129 & & \\
\hline & total & no & 722 & 55 & $78 \%(72-85 \%)$ & $98 \%$ (96-99\%) \\
\hline & & yes & 18 & 196 & & \\
\hline
\end{tabular}

\footnotetext{
analyses limited to participants with available data on both measured and self-reported weight and height.
} 
Table 5 Multivariate linear regression analysis of the association between ethnicity and difference between measured and estimated BMI

\begin{tabular}{|c|c|c|}
\hline & $\begin{array}{l}\text { Men } \\
\mathrm{B}, 95 \% \mathrm{Cl}\end{array}$ & $\begin{array}{l}\text { Women } \\
\mathrm{B}, 95 \% \mathrm{Cl}\end{array}$ \\
\hline \multicolumn{3}{|l|}{ Model 1} \\
\hline Turkish & $0.23(-0.09 ; 0.55)$ & $0.56(0.25 ; 0.88)^{* *}$ \\
\hline Moroccan & $-0.03(-0.36 ; 0.31)$ & $0.47(0.08 ; 0.85)^{*}$ \\
\hline Dutch & ref & ref \\
\hline \multicolumn{3}{|c|}{ Model 2: adjusted for age } \\
\hline Turkish & $0.21(-0.10 ; 0.53)$ & $0.67(0.34 ; 0.99)^{* * *}$ \\
\hline Moroccan & $-0.08(-0.42 ; 0.26)$ & $0.60(0.20 ; 0.99)^{* *}$ \\
\hline Dutch & ref & ref \\
\hline Age & $0.01(0.00 ; 0.02)^{*}$ & $0.02(0.00 ; 0.03)^{* *}$ \\
\hline \multicolumn{3}{|c|}{ Model 3: adjusted for age, measured BMI } \\
\hline Turkish & $-0.08(-0.40 ; 0.23)$ & $0.25(-0.09 ; 0.58)$ \\
\hline Moroccan & $-0.25(-0.58 ; 0.07)$ & $0.22(-0.17 ; 0.61)$ \\
\hline Dutch & ref & ref \\
\hline age & $0.00(-0.01 ; 0.01)$ & $0.0(-0.01 ; 0.01)$ \\
\hline measured BMl & $0.12(0.08 ; 0.15)^{* * *}$ & $0.09(0.06 ; 0.11)^{* * *}$ \\
\hline \multicolumn{3}{|c|}{ Model 4: adjusted for age, measured BMI and educational level } \\
\hline Turkish & $-0.16(-0.50 ; 0.19)$ & $0.16(-0.21 ; 0.52)$ \\
\hline Moroccan & $-0.33(-0.68 ; 0.03)$ & $0.20(-0.22 ; 0.61)$ \\
\hline Dutch & ref & ref \\
\hline age & $0.0(-0.01 ; 0.01)$ & $0.00(-0.01 ; 0.01)$ \\
\hline measured BMl & $0.12(0.09 ; 0.16)^{* * *}$ & $0.08(0.06 ; 0.11)^{* * *}$ \\
\hline educational level & $0.12(-0.18 ; 0.43)$ & $0.22(-0.10 ; 0.55)$ \\
\hline
\end{tabular}

$\mathrm{B}, 95 \% \mathrm{Cl}$, multivariate linear regression coefficient with $95 \%$ confidence interval.

${ }^{*} p<0.05,{ }^{* *} p<0.01,{ }^{* * *} p<0.001$ for comparison with Dutch ethnic group, ref $=$ reference.

One limitation was the fact that participants received written information on the measurements, which was required by the local Medical Ethical Committee. Therefore, we cannot exclude the possibility of self-reports being affected by the foreknowledge of the participants that they would be measured. However, we assume this influence was small, because the comprehensive health interview was completed prior to the health examination, which included a blood sample and a variety of other measurements. Moreover, the participants received written information one week prior to the health examination, whereas the oral explanation on the health examination was given after the interview.

Another potential source of bias could have resulted from the relatively low response rate and the limited number of participants in the ethnic subgroups. The response rate of the survey is comparable to that of other surveys in the Netherlands $[10,25,26]$. We therefore believe that these relative low response rates were not caused by a specific flaw in the study's design and are unlikely to indicate systematic bias. In addition, the number of individuals who did not receive their invitation because of incorrect residential addresses in the municipal registers is likely to be high because of the mobility of the population in Amsterdam [27]. Therefore, our actual response rate might be higher. We analyzed the possibility of selective non-response by age and socio-economic status and concluded that overall, income level as well as level of unemployment in our sample were comparable to that in the total Amsterdam population [28]. The response rates by age and ethnic groups were also analyzed and compared to the Dutch. We found comparable response rates among 18 to 69-year-old participants by ethnicity [24]. Because a non-weighted age-stratified sample was used for the analyses, the age groups were equally represented in each of the ethnic groups. Although the number of participants in each ethnic subgroup was relatively small, it was still large enough to demonstrate ethnic differences between measured and self-reported BMI-differences in women, but not large enough to show ethnic differences between true and estimated obesity prevalence. Among men, ethnic differences between true and estimated obesity prevalence were small, were not statistically significant and in our opinion had no clinical relevance. The same applied for ethnic differences between measured and self-reported BMI-differences in men.

Finally, as many comparisons were made, the findings in our study might have been caused by chance fluctuation. Post-hoc analyses were not applied as we basically tested pre-existing hypotheses and did not dredge the data for new findings. However, our findings need confirmation in a follow up study.

\section{Fit with previous evidence and explanations}

To our knowledge, this is the first study of discrepancies in BMI and obesity prevalence among adult men and women of Turkish and Moroccan origin. Previous studies on this topic among other immigrant groups showed that the underestimation of BMI and the obesity prevalence based on self-reports varies by ethnicity and gender. In Mexican American men and women and in African American women, discrepancies between measurements and self-reports were larger than in European Americans. However, among men and women of South Asian origin (Hindustani-Surinamese) and African-Surinamese women, discrepancies were smaller than among the Dutch [20-22].

In our study, the accuracy of self-reports was smaller among Turkish and Moroccan women than among Dutch women. Furthermore, the obesity prevalence among Turkish and Moroccan women with missing height or weight when using self-reports was higher than obesity among Turkish and Moroccan women with completed self-reports. Low educated Moroccan and Turkish women had incomplete self-reports more often 
than Moroccan and Turkish women with a minimum educational level of low vocational training. The single use of self-reported height and weight would have resulted in an underestimation of the obesity prevalence among Turkish women by $30 \%$ and among Moroccan women by $18 \%$. This issue was not described in the studies mentioned above [20-22]. Previous studies on the validity of self-reported weight and height among adolescents reported a high percentage of missing selfreports. As a possible explanation, the authors mentioned that the rapid growth of people during adolescence combined with the lack of recent measurements makes respondents less likely to know their current weight and height [29-33].

In our study, possible explanations for the high percentage of mis-reports and incomplete self-reports include the higher prevalence of obesity among migrant women compared with Dutch women and the tendency of obese people to under-report their weight more than nonobese people [18]. Further recall bias might play a role, related to the high illiteracy rate and low educational level in Turkish and Moroccan migrant women [34]. This is a plausible reason, as the inability to read and spell in low-income women has also been shown to be associated with a less accurate recall of their food intake [35]. Also, a lack of recent measurements might play a role. Regular measurements are important for both weight and height, because weight gain and a loss of height accompanies aging. As a result, respondents might be less likely to know their current weight and height [16]. Furthermore, reporting height and weight might be biased towards cultural ideals [20]. Because Turkish and Moroccan women over-reported weight, we believe that social desirability in answering did not play a large role in the assumption that the western ideal of a thin body size also applies to these groups.

\section{Conclusions}

The use of self-reported weight and height leads to an underestimation of BMI and obesity prevalence, both in the Dutch population and in Turkish and Moroccan migrant groups in the Netherlands. BMI based on selfreports is more likely to be underestimated in Turkish and Moroccan women than in the Dutch although this could be explained by their higher BMI. Among Turkish and Moroccan women, there is an additional underestimation of the obesity prevalence based on self-reports, because obese Turkish and Moroccan women have incomplete self-reports more often than those who are non-obese. In men, ethnicity is not associated with discrepancies between BMI and obesity prevalence based on self-reports and measurements. In addition to the general recommendation from previous studies to use measurements instead of self-reports to validly determine BMI and obesity prevalence in public health research, our results indicate that the use of measurements seems even more important in Turkish and Moroccan migrant women.

\section{Acknowledgements}

The authors would like to thank Mrs. A. Krol, Municipal Health Service Amsterdam for useful comments and suggestions on the analysis of the data; she was funded by the Public Health Service of Amsterdam. The data collection was conducted as part of the Amsterdam Health Monitor 2004 in collaboration with the National Institute for Public Health and the Environment (RIVM), Bilthoven, the Netherlands. The data collection was funded by the Municipality of Amsterdam, the Public Health Service of Amsterdam and the RIVM. We would like to thank the RIVM for funding the physical examination of the participants in our study. Further, the study and the manuscript preparation as well as the work of the authors $\mathrm{HD}, J U, \mathrm{DU}$ and AV was funded by the Public Health Service of Amsterdam. The work of LV was funded by the RIVM. The funding bodies have had no role in the study design, in the collection, analysis, and interpretation of data, in the writing of the manuscript, or in the decision to submit the manuscript for publication.

\section{Author details}

'Public Health Service of Amsterdam, Department of Epidemiology, Documentation and Health Promotion, P.O. Box 2200, 1000 CE Amsterdam, the Netherlands. ${ }^{2}$ Centre for Prevention and Health Services Research, National Institute for Public Health and the Environment, P.O. Box 1, 3720 BA Bilthoven, the Netherlands. ${ }^{3}$ University of Amsterdam, Faculty of Social and Behavioural Sciences, Amsterdam, the Netherlands.

\section{Authors' contributions}

HD was responsible for statistical analyses and interpretation of data. JU participated in the study concept, design and coordination as well as participating in analyses and interpretation of data and was also involved in critical revision of the manuscript. LV participated in the study concept, design and coordination and was also involved in critical revision of the manuscript. AV participated in the study concept and design and was involved in critical revision of the manuscript. DU participated in the study concept, design and coordination, participated in analyses and interpretation of data and was also involved in critical revision of the manuscript. All authors read and approved the final manuscript.

\section{Competing interests}

The authors declare that they have no competing interests.

Received: 21 December 2010 Accepted: 30 May 2011

Published: 30 May 2011

\section{References}

1. World Health Organization: Obesity: Preventing and Managing the Global Epidemic Geneva: WHO; 2000.

2. Salmond CE, Prior IAM, Wessen AF: Blood pressure patterns and migration: a 14-year cohort study of adult Tokelauans. Am J Epidemiol 1989, 130:37-52

3. Sundquist J, Johansson SE: The influence of socioeconomic status, ethnicity and lifestyle on body mass index in a longitudinal study. Int $J$ Epidemiol 1998, 27:57-63.

4. Uitewaal PJM, Manna DR, Bruijnzeels MA, Hoes AW, Thomas S: Prevalence of type 2 diabetes mellitus, other cardiovascular risk factors, and cardiovascular disease in Turkish and Moroccan immigrants in North West Europe: a systematic review. Prev Med 2004, 39:1068-76.

5. Dienst Onderzoek en Statistiek: Amsterdam in figures 2006 Amsterdam. Dienst Onderzoek en Statistiek, Gemeente Amsterdam; 2006, in Dutch.

6. Cornelisse-Vermaat JR, van den Brink HM: Ethnic differences in lifestyle and overweight in the Netherlands. Obesity 2007, 15:483-93.

7. Brussaard JH, van Erp-Baart MA, Brants HAM, Hulshof KFAM, Löwik MRH: Nutrition and health among migrants in The Netherlands. Public Health Nutr 2001, 4:659-664. 
8. Dijkshoorn H, Nierkens V, Nicolaou M: Risk groups for overweight and obesity among Turkish and Moroccan migrants in The Netherlands. Public Health 2008, 122:625-630

9. Köycü B, Kara T, Çamlidag O, Aydinli R, Verschuren WMM, Montfrans GA van: Risk factors for cardiovascular diseases in Turks in Amsterdam and in Ankara. Ned Tijdschr Geneesk 1997, 141:882-888, in Dutch.

10. Reijneveld SA: Reported health, lifestyles, and use of health care of first generation immigrants in the Netherlands: do socioeconomic factors explain their adverse position? J Epidemiol Community Health 1998, 52:298-304.

11. Ranganathan $M$, Bhopal R: Exclusion and inclusion of nonwhite ethnic minority groups in 72 North American and European cardiovascular cohort studies. PLoS Med 2006, 3:e44.

12. Ujcic-Voortman JK, Bos G, Baan CA, Verhoeff AP, Seidell JC: Obesity and body fat distribution: ethnic and socioeconomic differences between Turkish, Moroccan and Dutch ethnic groups in Amsterdam, the Netherlands. Obesity Facts 2011, 4:53-60.

13. Hosper K, Nierkens V, Nicolaou M, Stronks K: Behavioural risk factors in two generations of non-Western migrants: do trends converge towards the host population? Eur J Epidemiol 2007, 22:163-172.

14. Hill A, Roberts J: Body mass index: a comparison between self-reported and measured height and weight. J Public Health Med 1998, 20:206-210.

15. Rowland ML: Self-reported weight and height. Am J Clin Nutr 1990, 52:1125-1133.

16. Roberts RJ: Can self-reported data accurately describe the prevalence of overweight? Public Health 1995, 109:275-284.

17. Spencer EA, Appleby PN, Davey GK, Key TJ: Validity of self-reported height and weight in 4808 EPIC-Oxford participants. Public Health Nutr 2002, 5:561-565.

18. Visscher TLS, Viet L, Kroesbergen HT, Seidell JC: Underreporting of BMI in adults and its effect on obesity prevalence estimations in the period 1998 to 2001. Obesity 2006, 14:2054-2063.

19. Bolton-Smith C, Woodward M, Tunstall-Pedoe H, Morrison C: Accuracy of the estimated prevalence of obesity from self reported height and weight in an adult Scottish population. J Epidemiol Community Health 2000, 54:143-148.

20. Gillum RF, Sempos $C T$ : Ethnic variation in validity of classification of overweight and obesity using self-reported weight and height in American women and men: the Third National Health and Nutrition Examination Survey. Nutr J 2005, 4:27.

21. Valkengoed IGM, Nicolaou M, Stronks K: Ethnic differences in discrepancies between self-reported and measured weight, height and body mass index. Eur I Public Health 2010.

22. Johnson WD, Bouchard C, Newton RL Jr, Ryan DH, Katzmarzyk PT: Ethnic differences in self-reported and measured obesity. Obesity 2009, 17:571-7.

23. Krul AJ, Daanen HA, Choi H: Self-reported and measured weight, height and body mass index (BMI) in Italy, the Netherlands and North America. Eur J Public Health 2010.

24. Agyemang C, Ujcic-Voortman J, Uitenbroek D, Foets M, Droomers M: Prevalence and management of hypertension among Turkish, Moroccan and native Dutch ethnic groups in Amsterdam, the Netherlands: the Amsterdam Health Monitor Survey. J Hypertens 2006, 24:2169-2176.

25. Agyemang C, Denktas S, Bruijnzeels M, Foets M: Validity of the single-item question on self-rated health status in first generation Turkish and Moroccans versus native Dutch in the Netherlands. Public Health 2006, 120:543-550.

26. Uiters $E$, Devillé $W L$, Foets $M$, Groenewegen PP: Use of health care services by ethnic minorities in The Netherlands: do patterns differ? Eur J Public Health 2006, 16:388-393.

27. Slot J, Janssen M: Measurement of the Actual Quality of the Municipal Register in Amsterdam Amsterdam: Dienst Onderzoek en Statistiek, Gemeente Amsterdam; 2006, in Dutch.

28. Ujcic-Voortman JK, Wit MAS de, Uitenbroek DG, Tuinebreijer W, Viet L, Verhoeff AP: Physical examination and diagnostic interviews integrated into a general health survey of Amsterdam's multicultural population: the Amsterdam Health Monitor 2004-2005. TSG 2009, 87:351-359, in Dutch.

29. Jansen W, Looij-Jansen PM van de, Ferreira I, Wilde EJ de, Brug J: Differences in Measured and Self-Reported Height and Weight in Dutch Adolescents. Ann Nutr Metab 2006, 50:339-346.
30. Hauck FR, White L, Cao G, Woolf N, Strauss K: Inaccuracy of self-reported weights and heights among American-Indian adolescents. Ann Epidemiol 1995, 5:386-392.

31. Himes JH, Faricy $A$ : Validity and reliability of self-reported stature and weight of US adolescents. Am J Hum Biol 2001, 13:255-260.

32. Himes JH, Hannan P, Wall M, Neumark-Sztainer D: Factors associated with errors in self-reports of stature, weight, and body mass index in Minnesota adolescents. Ann Epidemiol 2005, 15:272-278.

33. Shannon B, Smiciklas-Wright $H$, Wang MQ: Inaccuracies in self-reported weights and heights of a sample of sixth-grade children. J Am Diet Assoc 1991, 91:675-678.

34. van der Vliet R, Ooijevaar J, Boerdam A, eds: Jaarrapportage Integratie 2010 [Annual report on Integration 2010] Den Haag/Heerlen: Statistics Netherlands; 2010.

35. Johnson RK, Soultanakis RP, Matthews DE: Literacy and body fatness are associated with underreporting of energy intake in US low-income women using the multiple-pass 24-hour recall: a doubly labelled water study. J Am Diet Assoc 1998, 98:1136-1140.

\section{Pre-publication history}

The pre-publication history for this paper can be accessed here: http://www.biomedcentral.com/1471-2458/11/408/prepub

doi:10.1186/1471-2458-11-408

Cite this article as: Dijkshoorn et al: Ethnic variation in validity of the estimated obesity prevalence using self-reported weight and height measurements. BMC Public Health 2011 11:408.

\section{Submit your next manuscript to BioMed Central and take full advantage of:}

- Convenient online submission

- Thorough peer review

- No space constraints or color figure charges

- Immediate publication on acceptance

- Inclusion in PubMed, CAS, Scopus and Google Scholar

- Research which is freely available for redistribution 